\title{
Is Adjuvant Endocrine Therapy Indicated for DCIS Patients After Complete Surgical Excision?
}

\author{
HIBA EL HAGE CHEHADE and KEFAH MOKBEL
}

The London Breast Institute, The Princess Grace Hospital, London, U.K.

\begin{abstract}
Data derived from pathological analysis, natural history, radiological characteristics, genomic profiling, and clinical outcome indicate that ductal carcinoma in situ (DCIS) is a heterogeneous disease; meaning that no single therapeutic strategy is best, but rather that treatment should be personalised and entail a rigorous multidisciplinary approach. The role of adjuvant endocrine therapy after surgical excision has been the subject of scientific debate in view of the in situ nature of this neoplasm. We reviewed the literature and summarised the evidence regarding the need for adjuvant endocrine therapy following complete surgical excision of DCIS through the identification of the most important outcomes, evaluation of quality of evidence, and assessment of the trade-offs involved. There is no scientific evidence that adjuvant endocrine therapy reduces the incidence of ipsilateral breast invasive recurrence or breast cancer mortality in the context of adequate local treatment of DCIS in the form of breast conserving surgery with clear surgical margins plus adjuvant radiotherapy or total mastectomy. Therefore, its routine use is not indicated. However, adjuvant endocrine therapy can be considered after a rigorous multidisciplinary discussion and patient counselling in a carefully selected subgroup of patients with high-risk estrogen receptor-positive DCIS.
\end{abstract}

The introduction of national mammographic screening programmes and the increasing use of digital mammography and magnetic resonance imaging (MRI) have dramatically changed the clinical presentation of DCIS which currently accounts for $20 \%$ of all screen-detected breast cancers (1-3).

This article is freely accessible online.

Correspondence to: Prof. Kefah Mokbel, The London Breast Institute, The Princess Grace Hospital, 42-52 Nottingham Place, London W1U 5NY, U.K. e-mail: kefahmokbel@hotmail.com

Key Words: Ductal Carcinoma in situ, endocrine therapy, review.
The prognosis of DCIS is usually excellent (4) as this is a stage 0 disease (1). By definition, the term "in situ" means there is an absence of basal membrane infiltration; hence, it is considered a precursor to invasive disease (5). Therefore, a true DCIS does not have the ability to spread (6). Consequently, wide local excision or mastectomy with or without the addition of radiotherapy in a subgroup of patients undergoing breast conserving surgery would achieve local control of the disease; hence, rendering the patient cured (7).

\section{Search Strategy}

Relevant articles were identified using the electronic database PubMed. Articles published up to December 2017 with no upper limit were included in the study. The following free text terms were used to search for relevant literature: "ductal carcinoma in situ or DCIS" and "endocrine therapy" or "postoperative or adjuvant endocrine therapy" or "Tamoxifen" or "aromatase inhibitors". Only articles published in English were selected. Studies identified were screened for those that were centered on the role, safety, and controversies of adjuvant endocrine therapy in DCIS patients, which is the focus of this review. Reference articles in this review were selected to provide a balanced and representative overview of a complex subject with an extensive base of published work.

\section{Adjuvant Endocrine Therapy and Clinical Outcome}

It was observed that in many institutions the treatment of DCIS is now almost as aggressive as that of the invasive disease (4), especially after the introduction of systemic adjuvant antihormone therapy. In 2000, tamoxifen, a selective estrogen receptor modulator (SERM), has gained approval by the Food and Drug Administration (FDA) to be used as an adjuvant endocrine therapy in DCIS patients (8). This was based on the first of the several clinical trials that have suggested potential benefits of endocrine therapy in cases of DCIS, the National Surgical Adjuvant Breast and Bowel Project NSABP B-24 trial (8-12). NSABP B-24 (8) was double-blinded, randomized, 
controlled trial enrolling 1804 DCIS patients who had previously undergone breast conserving surgery and whole breast radiotherapy. It randomized patients to receive tamoxifen versus placebo. Upon 5-year follow-up, less ipsilateral and contralateral breast cancer events were seen in the tamoxifen group than in the placebo group (8.2\% vs. $13.4 \%$ respectively, $p=0.0009$ ). In a follow-up study (9), the benefit was seen mainly in estrogen receptor (ER) positive DCIS patients. The second clinical trial to highlight the importance of tamoxifen in the setting of DCIS was the UK/ANZ DCIS trial (10). It enrolled 1701 DCIS patients who had undergone surgical excision to achieve negative margins. They were then randomized into $2 \times 2$ factorial trial of radiotherapy, tamoxifen, or both. Upon a median follow-up of 12.7 years, tamoxifen reduced the incidence of all new breast events $(\mathrm{HR}=0.71$, $95 \% \mathrm{CI}=0.58-0.88 ; p=0.002)$, reducing the risk of ipsilateral DCIS $(\mathrm{HR}=0.71,95 \% \mathrm{CI}=0.51-0.86 ; p=0.03)$ and contralateral tumors $(\mathrm{HR}=0.44,95 \% \mathrm{CI}=0.25-0.77 ; p=0.005)$, but having no effect on ipsilateral invasive disease $(\mathrm{HR}=0.95,95 \% \mathrm{CI}=0.66-$ $1.38 ; p=0.8)$. Nonetheless, tamoxifen had no apparent benefit among the cohort of patients who received radiotherapy (13). In view of the recent evidence that aromatase inhibitors are superior to tamoxifen in the treatment of postmenopausal women with ER positive invasive breast cancers (14), two large, double-blinded, randomized clinical trials were carried out to compare the performance of anastrozole versus tamoxifen in the adjuvant management of hormone-receptor positive, postmenopausal women with DCIS $(11,12)$. In the NSABP b-35 trial (12), 3104 DCIS patients with established clear surgical margins after breast conserving surgery and radiotherapy were enrolled in this study and randomized into either tamoxifen or anastrozole treatment arms. After a median follow-up of 9 years, there was a significant difference in the breast cancer-free interval in favour of the anastrozole group ( $\mathrm{HR}=0.73,95 \% \mathrm{CI}=0.56-0.96)$; however, this was mainly seen in the subgroup of postmenopausal patients younger than 60 years. The IBIS II trial (11) enrolled 2980 postmenopausal women with hormone- receptor positive surgically treated DCIS patients who were randomized into either adjuvant anastrozole or tamoxifen treatment arms. After a median follow-up of 7.2 years, there was no statistically significant difference in the overall recurrence rate between the two groups $(\mathrm{HR}=0.89,95 \% \mathrm{CI}=0.64-1.23)$; hence, suggesting the freedom of the patients to choose between the two medications.

Upon reviewing the results of the last two trials, one gets the impression that the use of endocrine therapy in the adjuvant setting for DCIS is rather mandatory; however, this is not necessarily the case. If we scrutinize the data available, we would have to reconsider the role of anti-hormone therapy in the treatment of DCIS. Both the B-24 and UK/ANZ trials did not base their patient selection to receive tamoxifen on the basis of ER status (13). This would have played a very crucial role in determining the effect of tamoxifen as an adjuvant therapy. Furthermore, $25 \%$ of the participants in the B-24 trial had positive or unknown surgical margins. The 15- year invasive ipsilateral breast tumour recurrence rate in the placebo arm was $17.4 \%$ in patients with positive surgical margins compared to $7.4 \%$ in those with negative ones. While in the tamoxifen group, even though tamoxifen decreased the incidence of ipsilateral invasive breast cancer to $11.5 \%$ in those with positive margins, it had no benefit among those with negative ones (7.4\% vs. $7.5 \%$ ) (15). This would highlight the fact that the decrease in the ipsilateral invasive disease is attributed to complete surgical clearance of the disease rather than the treatment role of tamoxifen. A similar local disease control with radiotherapy was seen in the UK/ANZ trial where tamoxifen had no effect on patients who received postoperative radiotherapy (10). Moreover, with $50 \%$ of DCIS recurrences being invasive in nature (16), the main goals of DCIS management are to prevent future invasive disease (13) in addition to improving overall survival, both of which were not established in previous trials. In their meta-analysis of tamoxifen $v s$. no additional treatment in DCIS patients, Staley et al. (17) showed that while tamoxifen after surgical treatment of DCIS reduced the risk of both ipsilateral and contralateral DCIS $\quad(\mathrm{HR}=0.75 ; \quad 95 \% \mathrm{CI}=0.61-0.92$ and $\mathrm{RR}=0.50$; $95 \% \mathrm{CI}=0.28-0.87$ ), respectively, as well as contralateral invasive cancer $(\mathrm{RR}=0.57 ; 95 \% \mathrm{CI}=0.39-0.83)$, there was no significant reduction in ipsilateral invasive cancer $(\mathrm{HR}=0.79$; 95\% CI=0.62-1.01). Moreover, there was no evidence of a difference in all-cause mortality $(\mathrm{RR}=1.11 ; 95 \% \mathrm{CI}=0.89-1.39)$.

\section{Conclusion}

In summary, we believe that the routine use of adjuvant endocrine therapy in DCIS patients is questionable, provided that a thorough histopathological examination is performed and invasive malignancy is excluded, an issue that can be challenging in extensive DCIS lesions. These anti-hormonal drugs have well-established side-effects with a significant impact on patient's quality of life (11). Most frequently reported side-effects of endocrine therapy are those related to menopausal symptoms like hot flashes, vaginal dryness, dyspareunia, loss of libido, mood swings, and night sweats. Other adverse effects associated with tamoxifen use include vaginal bleeding or discharge, cataract, venous thromboembolic events, ischemic cerebrovascular events, and endometrial cancer. On the other hand, cardiac failure and other cardiovascular events, hypercholesterolemia, musculoskeletal disorders, including new-onset osteoporosis, fractures, and arthralgia are recognised adverse effects of aromatase inhibitors (18-24). DCIS is an in situ disease with an excellent 10 -year survival rate of $98 \%$ (4). Although the annual risk of developing a contralateral in situ or invasive disease is elevated at $0.6 \%$ in the absence of genetic aberration (25), the risk is very small, and the patients are 
routinely followed-up with the ability to detect and manage recurrent or new breast malignancy at an early stage. Since studies have shown that tamoxifen may reduce ipsilateral DCIS but not invasive breast cancer (17), and DCIS recurrence does not influence overall survival, most patients with DCIS can be safely spared endocrine therapy. DCIS theoretically should not metastasize nor relapse in distant organs; therefore, the management should focus on local disease control $(8,26)$ rather than bombarding the body with systemic overtreatment. The benefits established with tamoxifen in terms of decreasing the risk of contralateral all breast events and possibly ipsilateral DCIS (17) may be explained in a chemoprevention context rather than an actual treatment where tamoxifen seems to have an impact on the prevention of invasive breast cancer among high risk women in general and in women with DCIS only on the "normal" breast" or contralateral breast (4). This potential chemoprevention benefit should be considered in the context of the adverse effects of endocrine therapy and regular surveillance of patients with DCIS during the evaluation of trade-offs. However, the evidence does not exclude the use of tamoxifen in carefully selected cases. Studies have shown that DCIS recurrence is associated with younger age, higher grade, large tumors, and positive or close margins (27-30). This group of DCIS patients as well as those not undergoing postoperative radiotherapy when indicated may be offered adjuvant endocrine therapy after testing for DCIS receptors, multidisciplinary discussion, and careful patient counselling. Furthermore, in addition to the consideration of the clinical picture, future research should focus on accurate molecular and genomic profiling of DCIS in order to guide precise individualized management and avoid overtreatment and hence a rather collateral damage of breast cancer screening.

\section{Conflicts of Interest}

The Authors report no conflicts of interest.

\section{Acknowledgements}

This review was funded by grants from the Breast Cancer Hope Foundation (London, U.K.).

\section{References}

1 American Cancer Society. Cancer Facts \& Figures 2015 Available at https://www.cancer.org/content/dam/CRC/PDF/ Public/8577.00.pdf. Accessed December 6, 2017.

2 Smart CR, Myers MH and Gloeckler LA: Implications from SEER data on breast cancer management. Cancer 3: 41787e9, 1978.

3 Van Steenbergen LN, Voogd AC, Roukema JA, Louwman WJ, Duijm LE, Coebergh JW and van de Poll-Franse LV: Screening caused rising incidence rates of ductal carcinoma in situ of the breast. Breast Cancer Res Treat 115(1): 181e3, 2009.
4 Tjalma W: Is anti-hormonal treatment in DCIS of the breast a need? Facts Views Vis Obgyn 8(3): 179-181, 2016.

5 Van Cleef A, Altintas S, Huizing M Papadimitriou K, Van Dam $\mathrm{P}$ and Tjalma W: Current view on ductal carcinoma in situ and importance of the margin thresholds: A review. Facts Views Vis Obgyn 6(4): 210-218, 2014.

6 Nicholson S, Hanby A, Clements K, Kearins O, Lawrence G, Dodwell D, Bishop H, Thompson A and Sloane Project Steering Group: Variations in the management of the axilla in screendetected ductal carcinoma in situ: evidence from the UK NHS breast screening programme audit of screen detected DCIS. Eur J Surg Oncol 41(1): 86-93, 2015.

7 Al-Hilli Z, Hieken TJ and Boughey JC: Axillary Ultrasound in the Management of the Newly Diagnosed Breast Cancer Patient. Breast J 21(6): 634-641, 2015.

8 Fisher B, Dignam J, Wolmark N, Wickerham DL, Fisher ER, Mamounas E, Smith R, Begovic M, Dimitrov NV, Margolese RG, Kardinal CG, Kavanah MT, Fehrenbacher L and Oishi RH: Tamoxifen in treatment of intraductal breast cancer: National Surgical Adjuvant Breast and Bowel Project B-24 randomised controlled trial. Lancet 353(9169): 1993-2000, 1999.

9 Allred DC, Anderson SJ, Paik S, Wickerham DL, Nagtegaal ID, Swain SM, Mamounas EP, Julian TB, Geyer CE Jr, Costantino JP, Land SR and Wolmark N: Adjuvant tamoxifen reduces subsequent breast cancer in women with estrogen receptorpositive ductal carcinoma in situ: a study based on NSABP protocol B-24. J Clin Oncol 30(12): 1268-1273, 2012.

10 Cuzick J, Sestak I, Pinder SE, Ellis IO, Forsyth S, Bundred NJ, Forbes JF, Bishop H, Fentiman IS and George WD: Effect of tamoxifen and radiotherapy in women with locally excised ductal carcinoma in situ: Long-term results from the UK/ANZ DCIS trial. Lancet Oncol 12(1): 21-29, 2011.

11 Forbes JF, Sestak I, Howell A, Bonanni B, Bundred N, Levy C, von Minckwitz G, Eiermann W, Neven P, Stierer M, Holcombe C, Coleman RE, Jones L, Ellis I, Cuzick J and IBIS-II investigators: Anastrozole versus tamoxifen for the prevention of locoregional and contralateral breast cancer in postmenopausal women with locally excised ductal carcinoma in situ (IBIS-II DCIS): a double-blind, randomized controlled trial. Lancet 387(10021): 866-873, 2016.

12 Margolese RG, Cecchini RS, Julian TB, Ganz PA, Costantino JP, Vallow LA, Albain KS, Whitworth PW, Cianfrocca ME, Brufsky AM, Gross HM, Soori GS, Hopkins JO, Fehrenbacher L, Sturtz K, Wozniak TF, Seay TE, Mamounas EP and Wolmark N: Anastrozole versus tamoxifen in postmenopausal women with ductal carcinoma in situ undergoing lumpectomy plus radiotherapy (NSABP B-35): a randomised, double-blind, phase 3 clinical trial. Lancet 387(10021): 849-856, 2016.

13 Kuerer HM: Rational individualised selection of adjuvant therapy for ductal carcinoma in situ. Lancet Oncol 12(1): 2-3, 2011.

14 Early Breast Cancer Trialists' Collaborative Group: Aromatase inhibitors versus tamoxifen in early breast cancer: patient-level meta-analysis of the randomised trials. Lancet 386(10001): 1341-1352, 2015.

15 Wapnir IL, Dignam JJ, Fisher B, Mamounas EP, Anderson SJ, Julian TB Land SR, Margolese RG, Swain SM, Costantino JP and Wolmark N: Long-term outcomes of invasive ipsilateral breast tumor recurrences after lumpectomy in NSABP B-17 and B-24 randomized clinical trials for DCIS. J Natl Cancer Inst 103(6): 478-488, 2011. 
16 Kerlikowske K, Molinaro A, Cha I, Ljung BM, Ernster VL, Stewart K, Chew K, Moore DH 2nd and Waldman F: Characteristics associated with recurrence among women with ductal carcinoma in situ treated by lumpectomy. J Natl Cancer Inst 95(22): 1692-702, 2003.

17 Staley H, McCallum I and Bruce J: Postoperative Tamoxifen for ductal carcinoma in situ: Cochrane systematic review and metaanalysis. Breast 23: 546-551, 2014.

18 Freedman AN, Yu B, Gail MH, Costantino JP, Graubard BI, Vogel VG, Anderson GL and McCaskill-Stevens W: Benefit/risk assessment for breast cancer chemoprevention with raloxifene or tamoxifen for women age 50 years or older. J Clin Oncol 29: 2327-2333, 2011

19 Howell A, Cuzick J, Baum M, Buzdar A, Dowsett M, Forbes JF, Hoctin-Boes G, Houghton J, Locker GY and Tobias JS; ATAC Trialists' Group: Results of the ATAC (Arimidex, Tamoxifen, Alone or in Combination) trial after completion of 5 years' adjuvant treatment for breast cancer. Lancet 365(9453): 60-62, 2005.

20 Breast International Group (BIG) 1-98 Collaborative Group; Thurlimann B, Keshaviah A, Coates AS, Mouridsen H, Mauriac L, Forbes JF, Paridaens R, Castiglione-Gertsch M, Gelber RD, Rabaglio M, Smith I, Wardley A, Price KN and Goldhirsch A: A comparison of letrozole and tamoxifen in postmenopausal women with early breast cancer. N Engl J Med 353(26): 27472757, 2005.

21 Coombes RC, Hall E, Gibson LJ, Paridaens R, Jassem J, Delozier T, Jones SE, Alvarez I, Bertelli G, Ortmann O, Coates AS, Bajetta E, Dodwell D, Coleman RE, Fallowfield LJ, Mickiewicz E, Andersen J, Lønning PE, Cocconi G, Stewart A, Stuart N, Snowdon CF, Carpentieri M, Massimini G, Bliss JM and van de Velde $\mathrm{C}$ for the Intergroup Exemestane Study: A randomized trial of exemestane after two to three years of tamoxifen therapy in postmenopausal women with primary breast cancer. N Engl J Med 350(11): 1081-1092, 2004.

22 Goss PE, Ingle JN, Martino S, Robert NJ, Muss HB, Piccart MJ, Castiglione M, Tu D, Shepherd LE, Pritchard KI, Livingston RB, Davidson NE, Norton L, Perez EA, Abrams JS, Cameron DA, Palmer MJ and Pater JL: Randomized trial of letrozole following tamoxifen as extended adjuvant therapy in receptorpositive breast cancer: updated findings from NCIC CTG MA.17. J Natl Cancer Inst 97(17): 1262-1271, 2005.

23 Boccardo F, Rubagotti A, Puntoni M Guglielmini P, Amoroso D, Fini A, Paladini G, Mesiti M, Romeo D, Rinaldini M, Scali S, Porpiglia M, Benedetto C, Restuccia N, Buzzi F, Franchi R, Massidda B, Distante V, Amadori D and Sismondi P: Switching to anastrozole versus continued tamoxifen treatment of early breast cancer: preliminary results of the Italian Tamoxifen Anastrozole trial. J Clin Oncol 23(22): 5138-5147, 2005.
24 Wasan KM, Goss PE, Pritchard PH Shepherd L, Palmer MJ, Liu S, Tu D, Ingle JN, Heath M, Deangelis D and Perez EA: The influence of letrozole on serum lipid concentrations in postmenopausal women with primary breast cancer who have completed 5 years of adjuvant tamoxifen (NCIC CTG MA.17L). Ann Oncol 16(5): 707-715, 2005.

25 Tuttle TM, Jarosek S, Habermann EB, Arrington A, Abraham A, Morris TJ and Virnig BA: Increasing rates of contralateral prophylactic mastectomy among patients with ductal carcinoma in situ. J Clin Oncol 27(9): 1362-1367, 2009.

26 Fisher B, Bryant J, Dignam JJ, Wickerham DL, Mamounas EP, Fisher ER, Margolese RG, Nesbitt L, Paik S, Pisansky TM and Wolmark $\mathrm{N}$ for the National Surgical Adjuvant Breas and Bowel Project: Tamoxifen, radiation therapy, or both for prevention of ipsilateral breast tumor recurrence after lumpectomy in women with invasive breast cancers of one centimeter or less. J Clin Oncol 20(20): 4141-4149, 2002.

27 Houghton J, George WD, Cuzick J, Duggan C, Fentiman IS and Spittle M for UK Coordinating Committee on Cancer Research; Ductal Carcinoma in situ Working Party; DCIS trialists in the UK, Australia, and New Zealand: Radiotherapy and tamoxifen in women with completely excised ductal carcinoma in situ of the breast in the UK, Australia, and New Zealand: randomised controlled trial. Lancet 362(9378): 95-102, 2003.

28 Eng-Wong J, Costantino JP and Swain SM: The impact of systemic therapy following ductal carcinoma in situ. J Natl Cancer Inst Monogr 2010(41): 200-203, 2010.

29 Hughes LL, Wang M, Page DL, Gray R, Solin LJ, Davidson NE, Lowen MA, Ingle JN, Recht A and Wood WC: Local excision alone without irradiation for ductal carcinoma in situ of the breast: a trial of the Eastern Cooperative Oncology Group. J Clin Oncol 27(32): 5319-5324, 2009.

30 Silverstein MJ and Lagios MD: Choosing treatment for patients with ductal carcinoma in situ: fi ne tuning the University of Southern California/Van Nuys Prognostic Index. J Natl Cancer Inst Monogr 2010(41): 193-196, 2010. 